\title{
Malacoplaquia en urologia: aportación de seis casos y revisión de la literatura
}

\author{
Velásquez López Juan G, Vélez Hoyos A, Uribe Arcila JF. \\ Hospital Pablo Tobón Uribe. Medellín-Colombia
}

Actas Urol Esp 2006; 30(6): 610-618

\section{RESUMEN}

MALACOPLAQUIA EN UROLOGÍA: APORTACIÓN DE SEIS CASOS Y REVISIÓN DE LA LITERATURA

La Malacoplaquia (MLP) es una enfermedad granulomatosa crónica poco frecuente. Se piensa es secundaria a una alteración en el sistema fagocitario humano y se caracteriza por la presencia de una o varias tumoraciones que pueden aparecer virtualmente en cualquier parte del organismo, conllevando a un diagnóstico erróneo de malignidad. El tracto urinario es el principalmente comprometido. El estudio patológico de estas lesiones muestra un tejido infiltrado por células inflamatorias (macrófagos e histiocitos) con presencia de inclusiones intracitoplasmáticas denominadas los cuerpos de Michaelis-Gutmann.

Usualmente es una enfermedad benigna autolimitada y se asocia a infecciones urinarias (ITU) a repetición, pero la mayoria de las veces responde de manera adecuada a un tratamiento prolongado con quinolonas.

Aportamos seis casos diagnosticados en nuestra institución durante un periodo de ocho años, de los cuales especificamos también su manejo. Se realiza además una revisión de la literatura actual.

Palabras Clave: Malacoplaquia. Tumor vejiga. Cuerpos de Michaelis-Gutmann. Quinolonas. Placa tracto genitourinario. Neoplasia genitourinaria. Von Hansemann.

\section{ABSTRACT}

MALAKOPLAKIA IN UROLOGY: SIX CASES REPORT AND REVIEW OF THE LITERATURE

Malakoplakia (MLP) is a rare chronic granulomatous disease that is believed to happen because of an alteration in the bacterial phagocytic system. This entity is characterized by one or multiple tumorations that can appear in any part of the body leading to it's misdiagnosing as a malignant condition. The genitourinary tract is frequently involved. Pathologic study of these lesions shows tissue infiltrated by inflammatory cells (macrophages and hystiocites) with intracytoplasmatic inclusions, which are known as Michaelis-Gutmann bodies.

Usually is a benign condition self-limited and is associated with recurrent urinary tract infection (UTI), this condition has a good response to prolonged treatment with fluoroquinolones.

We will report six cases that were diagnosed and treatment in our institution during an eight year period. We report still a review of the available literature.

Keywords: Malakoplakia. Malacoplakia. Bladder tumor. Michaelis-Gutmann bodies. Fluoroquinolones. Genitourinary tract plaque. Genitourinary neoplasms. Von Hansemann.

$\mathrm{L}^{2}$ a Malacoplaquia (MLP) es una enfermedad granulomatosa crónica, causada al parecer por un defecto en el sistema fagocitario bacteriano. Es una rara entidad que se caracteriza por la presencia de una o varias tumoraciones, en cualquier parte del organismo, de ahí la confusión de su diagnóstico con malignidad. El tracto genitou- rinario se ve afectado hasta en un 75\% de los casos. Los tejidos comprometidos típicamente son consistentes con una infiltración masiva por células inflamatorias (macrófagos e histiocitos) con inclusiones intracitoplasmáticas características (cuerpos de Michaelis-Gutmann). Usualmente autolimitada y asociada a infecciones urina- 
rias repetidas, con excelente respuesta a períodos prolongados de tratamiento con quinolonas. En este artículo se aportan seis casos presentados en una misma institución de tercer nivel de complejidad en un período de ocho años y se realiza una revisión completa de la literatura.

\section{APORTACIÓN DE CASOS}

Caso 1: Lactante masculino de 4 meses de edad, nacido y residente en Medellín, que consultó por cuadro de 3 días de evolución de orquialgia izquierda asociada a eritema y edema progresivos del saco escrotal ipsilateral, la revisión por sistemas fue negativa y no había antecedentes peri o postnatales de importancia. El examen físico reveló unos signos vitales normales para la edad y como positivo eritema y edema de hemiescroto con sensibilidad marcada a la manipulación del testículo izquierdo. Las pruebas analíticas solicitadas al ingreso mostraron un hemoleucograma y citoquímico de orina normales. $\mathrm{El}$ eco doppler testicular presenta marcado engrosamiento epididimal izquierdo asociado a pequeña colección; el paciente sale con diagnóstico de epididimitis aguda y se le instaura tratamiento con cefalexina y acetaminofén más medidas locales. Tres días después en la cita control, la madre refiere leve mejoría y fiebre subjetiva ocasional, sin cambios al examen físico. 11 días después consulta de nuevo y persiste con testículo izquierdo aumentado de tamaño e indurado por lo que se solicita eco de control que presenta región heterogénea testicular izquierda, se sugiere descartar neoplasia tipo teratoma, por lo que se realiza orquidectomía radical izquierda, previo aporte de marcadores tumorales (Beta HCG, Alfa fetoproteína) negativos, con abordaje inguinal y ligadura temprana del cordón, proximal al anillo inguinal profundo. Se obtuvo una masa dura intratesticular sugestiva de tumor que midió $3 \times 2 \times 1 \mathrm{~cm}$, con presencia al corte de áreas irregulares y fibrosas de color amarillo. Los cortes de patología mostraron un proceso inflamatorio benigno constituido por abundantes células inflamatorias: linfocitos, plasmocitos, células gigantes y focalmente presencia de histiocitos; en medio de éstas se reconocen células con halo claro consistentes, con cuerpos de Michaelis-
Gutmann que sugiere el diagnóstico de MLP. El urocultivo solicitado al ingreso demostró colonización por E. coli con mas de $10^{5}$ Unidades Formadoras de Colonias (UFC).

El paciente evolucionó satisfactoriamente en su postoperatorio.

Caso 2: Mujer de 52 años, remitida de un hospital rural por cuadro de dos meses de evolución de dolor en hipocondrio y flanco derecho, asociado a fiebre subjetiva, escalofrío, diaforesis, pérdida subjetiva de peso y sensación de masa abdominal dolorosa. A la revisión por sistemas presentaba edema de miembros inferiores ocasional. Con antecedente de Diabetes mellitus tipo 2 en tratamiento con glibenclamida. Examen físico, frecuencia cardiaca (FC) 76 por minuto, presión arterial (PA) 140/80. Como hecho positivo se encontró gran masa palpable de aproximadamente $15 \mathrm{~cm}$. en flanco y hasta fosa iliaca derecha, indurada y dolorosa. La analítica mostró hemograma con 16.200 leucocitos a expensas de polimorfonucleares (PMN), hemoglobina de 13 $\mathrm{g} / \mathrm{dl}$ y VSG de $10 \mathrm{~mm} / \mathrm{h}$; citoquímico de orina que presentó orina turbia con glucosuria y un sedimento con piuria y presencia de $>50$ eritrocitos por campo de alto poder; creatinina de $0,81 \mathrm{y}$ glicemia en 467; urocultivo positivo para $10^{5} \mathrm{UFC}$ de E. coli. Se solicita ecografía abdominal con la siguiente lectura: presencia de gran masa retroperitoneal que ocupa la topografía del músculo psoas derecho, con efecto de masa sobre el riñón, en relación con gran absceso que compromete la grasa pararrenal posterior. Signos de nefropatía inespecífica derecha, con imagen ecogénica que pudiera corresponder a angiomiolipoma o nefronía derecha. Se inicia tratamiento empírico y se programa cirugía abierta tipo laparotomía, con realización de nefrectomía radical derecha y resección de masa retroperitoneal que invade parcialmente al músculo psoas, pared abdominal posterolateral y parte de la tercera porción del duodeno. En el postoperatorio la paciente evoluciona regularmente con hipotensión sostenida, cetosis y oliguria, de las cuales se recupera satisfactoriamente y es dada de alta 10 días después, con un tratamiento a base de ciprofloxacina durante un mes. El resultado de patología refiere riñón derecho de $400 \mathrm{~g}$, con tejidos blandos peri- 
rrenales adheridos a su superficie, que al corte se continúan hacia el parénquima renal en forma de tejido blando formando nódulos lobulados, irregulares, de color amarillo que llegan hasta las cavidades renales, además presencia de cavidades con contenido purulento, microscópicamente, presencia de áreas de necrosis, acúmulos de histiocitos, en ocasiones espumosos con PMN y se aprecian numerosos cuerpos de Michaelis-Gutmann (Figs. 1, 2 y 3). Diagnóstico definitivo MLP. Es de reseñar que este caso se confirmó por el Instituto de Patología de las Fuerzas Armadas de Washington por los doctores Mostoffi, Brinsko y Sesterhenn del departamento de uropatologia ${ }^{21}$.

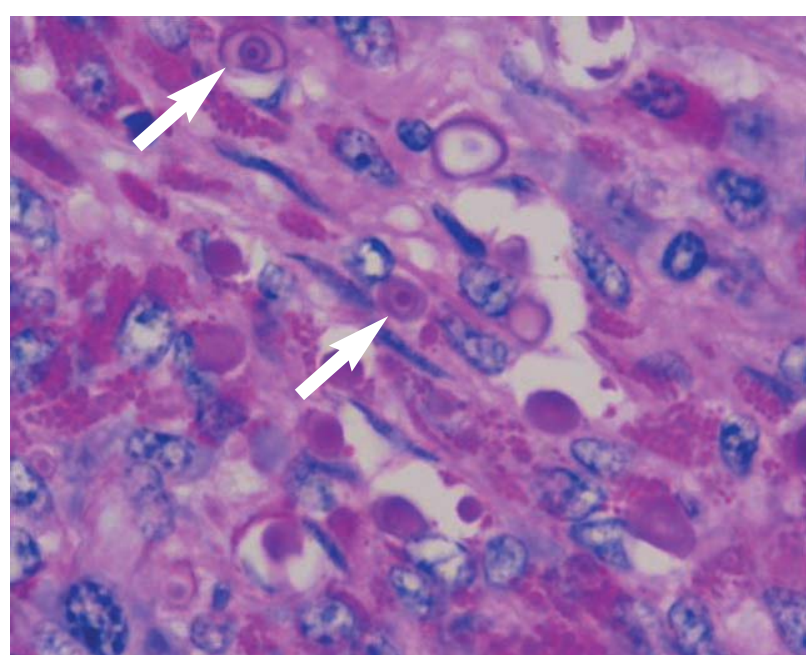

FIGURA 1. Imagen microscópica (40x) mostrando histiocitos con gran citoplasma con cuerpos de MichaelisGutmann.

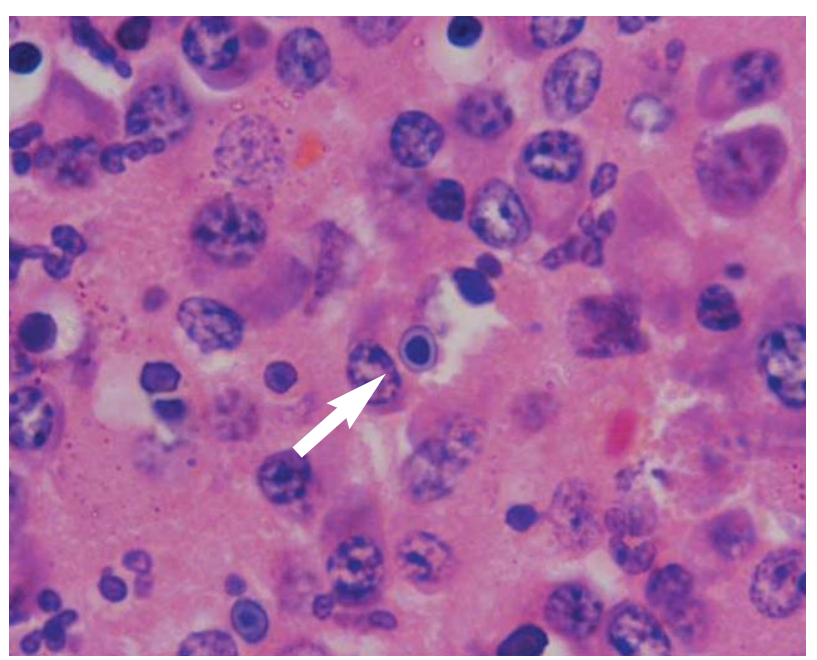

FIGURA 2. Cuerpos de Michaelis-Gutmann confirmados con la coloración PAS.

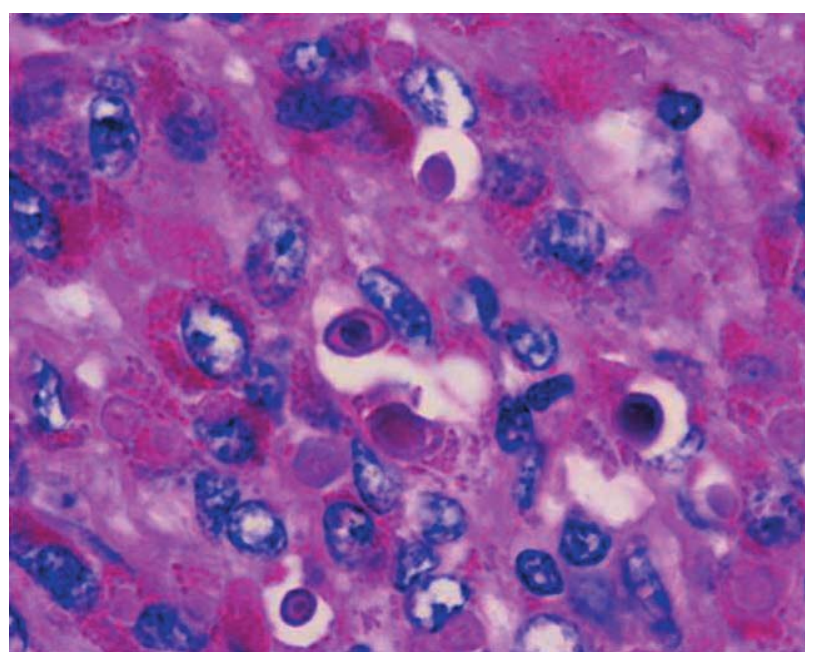

FIGURA 3. Cuerpos de Michaelis-Gutmann confirmados con la coloración PAS en una muestra de próstata (40x).

Caso 3: Varón de 60 años, con cuadro clínico de 4 meses de evolución de sintomatología irritativa y obstructiva urinaria, consistente en disuria, polaquiuria, goteo postmiccional, disminución del calibre del chorro y retención urinaria en una ocasión. Al examen físico se encontró un paciente en buenas condiciones generales y como hallazgo positivo, un tacto rectal con una próstata aumentada de tamaño grado II adenomatosa y de aspecto benigno. PSA de $6,30 \mathrm{ng} / \mathrm{ml}$. La ecografia transrectal presentó próstata de tamaño $41 \times 27 \times 42 \mathrm{~mm}$, con imagen hiperecoica en topografia de la zona central y transicional compatible con nódulo adenomatoso. Se diagnostica hiperplasia prostática (HPB) y se realiza Resección TransUretral (RTU) de próstata. Los cortes histológicos, presentan focos de hiperplasia estromal con glándulas proliferadas en número y tamaño, sin displasia, además presencia de zonas periféricas de atrofia y focos de inflamación con acúmulos de histiocitos que en el citoplasma muestran característicamente cuerpos de Michaelis Gutmann.

Caso 4: Varón de 67 años de edad, con cuadro clínico de 6 meses de evolución consistente en nocturia, disminución del calibre del chorro miccional, hematuria, polaquiuria, goteo postmiccional y retención urinaria. Al examen físico se encuentra en buenas condiciones generales, al tacto rectal se halla próstata aumentada de tamaño, nodular, grado III, firme en el lóbulo derecho 
y no dolorosa. Se solicita antígeno específico de próstata. Su resultado fue de $263 \mathrm{ng} / \mathrm{dl}$. Se programa biopsia transrectal ecodirigida y su resultado (Hospital Pablo Tobón Uribe) presenta HPB. Una nueva ecografía dos meses después documenta una glándula de $83 \mathrm{cc}$ de volumen con múltiples nódulos hipoecoicos en área central. Con diagnóstico de HPB grado III se programa para adenomectomía de próstata retropúbica. El informe de patología, presentó macroscópicamente nódulos amarillos blandos y áreas de aspecto necrótico; los cortes histológicos, aportaron a la evaluación de las zonas amarillas colecciones de histiocitos y linfocitos. Dentro de los histiocitos se encontró gran cantidad de inclusiones intracitoplasmáticas concéntricas y redondas que corresponden a cuerpos de MichaelisGutmann los cuales fueron confirmados con la coloración de PAS (periodic acid-Schiff).

Caso 5: Varón, de 70 años, con cuadro clínico de infecciones urinarias a repetición asociado a sintomatologia obstructiva urinaria consistente en nocturia, disminución del calibre del chorro miccional, goteo postmiccional y episodio de retención urinaria en dos ocasiones. Al examen físico sólo al tacto rectal se muestra una próstata aumentada de tamaño, grado IV. El antígeno prostático fue de $10 \mathrm{ng} / \mathrm{dl}$. Se le solicitó una ecografía renal y vías urinarias que presentó como positivo una próstata aumentada de tamaño. Se realizó RTU de próstata y se enviaron muestras a patología. La descripción de patología de los fragmentos obtenidos de la próstata fue presencia de glándulas de luz recta revestidas con epitelio cilíndrico de forma y tamaño uniforme, sin displasia ni atipia, en el lado izquierdo, foco de inflamación aguda y crónica con abundantes histiocitos y presencia de cuerpos de MichaelisGutmann intra y extracelulares; se confirman con tinciones de PAS y Van Kossa.

Caso 6: Varón, de 70 años quien consultó por un antígeno de próstata con un valor de 37 ng/dl. En el examen físico al tacto rectal se palpa nódulo indurado en el lado derecho. Se solicita toma de biopsias transrectales ecodirigidas y el resultado es presencia de adenocarcinoma de próstata con gleason $3+3=6$ en el lado derecho y en el lado izquierdo foco patognomónico de malacoplaquia. El paciente no continuó el seguimiento en la institución por lo que se desconoce su evolución final.

\section{DISCUSIÓN}

Dentro de las enfermedades poco frecuentes en el aparato genitourinario se encuentra la MLP, enfermedad granulomatosa crónica, observada inicialmente en humanos por el profesor Von Hansemann, el 14 de mayo de 1901, persona a quien se le atribuye y que dio el nombre de MLP, después de evaluar y estudiar dicha patología. La describe y publica por primera vez en 1903 en Berlín (Alemania) con el título : "Uber Malakoplakie der Harnblase" (sobre la MLP de la vejiga urinaria), el profesor después de su observación le comenta el caso y sus detalles a su asistente el Dr. Gutmann, éste, en colaboración con el bioquímico experto, el Dr. Michaelis, realizan una segunda publicación un año más tarde acerca de los hallazgos en la patología descrita por el profesor $^{2}$ describiendo de manera detallada las estructuras redondas intracelulares que actualmente llevan sus nombres y que se consideran marcadores histológicos característicos de esta lesión ${ }^{4,28}$. La palabra MLP es derivada del griego "malakos" (blando) y "plakos" (placa). Macroscópicamente se observan placas (granulomas) friables de color amarillo en la mucosa. Microscópicamente, corresponde a la presencia de macrófagos localizados en la muscularis propia, típicamente de gran tamaño, con forma poligonal y citoplasma eosinofilico (cuerpos de Von Hansemann) con presencia de cuerpos de inclusión intracitoplasmáticos calcificados (cuerpos de Michaelis-Gutmann) ${ }^{1}$, estos últimos de manera constante son intensamente PAS positivos y son el resultado de fagolisosomas que contienen fragmentos de bacterias incompletamente destruidas con depósitos anormales de hierro y calcio ${ }^{19}$.

La MLP en el 80\% de los casos esta localizada en el sistema genitourinario, más frecuentemente en la vejiga ${ }^{13,17,27}$, seguida por el uréter, la pelvis y el parénquima renal ${ }^{17,19,21}$ pero puede virtualmente afectar cualquier órgano. Están descritos: pulmón ${ }^{5}$, cerebro ${ }^{6}$, glándulas adrenales ${ }^{1}$, páncreas ${ }^{7}$, ganglios mesentéricos ${ }^{1}$, tiroides ${ }^{8}$, globo ocular ${ }^{9}$, piel ${ }^{10}$, hueso ${ }^{11}$ y el tracto gastrointes- 
tinal ${ }^{1,4,12,21}$, siendo en este último el recto, sigmoides y colón derecho los sitios más frecuentemente comprometidos en orden descendente.

En la literatura mundial existe la descripción de dos grandes experiencias en una misma clínica, realizadas en 1977 y 1989 con 10 y 9 casos respectivamente, recientemente Ballesteros ${ }^{29}$ aporta 4 casos. Nosotros aportamos 6 casos presentados en una única institución, el Hospital Pablo Tobón Uribe, en Medellín. En Colombia esta entidad se ha considerado exótica. El primer caso publicado fue en 1997 por Raad R, Vélez A, Ángel A y Uribe $\mathrm{JF}^{22}$. En la mayoría de los casos el diagnóstico lo establece el patólogo, motivados por esto, consideramos de gran interés informar estos seis casos localizados en el tracto urinario y así ayudar a crear interés y experiencia en el diagnóstico de esta entidad poco usual.

\section{ETIOLOGÍA}

Múltiples teorías se han propuesto para explicar la patogénesis de esta enfermedad. Se describe un origen infeccioso, un estado de inmunosupresión de base, una neoplasia, una enfermedad sistémica o incluso corresponda a un desorden genético.

Existe evidencia de un origen infeccioso por el hecho de encontrar y lograr aislar en evaluaciones electro-microscópicas bacterias coliformes en fagolisosomas de los macrófagos de pacientes con la enfermedad ${ }^{14,15}$, además, la mayoría de los pacientes están cursando o tienen el antecedente de enfermedades infecciosas crónicas, o más común infecciones urinarias, con presencia en un $80-90 \%$ de Escherichia coli. Sin embargo no se le puede atribuir un papel etiológico principal a esta última, pues también están descritos Klebsiella, Proteus, Mycobacterium, Staphilococcus y hongos ${ }^{1,8}$.

Varios hechos apuntan a que sea el resultado a una enfermedad sistémica, como es encontrar microorganismos no digeridos dentro de los lisosomas de macrófagos en la población afectada, que sugiere una alteración en estos; más aún, se confirmó con estudios celulares e inmunoensayos que los macrófagos de las personas afectadas por MLP tienen un déficit de Guanosin monofosfato cíclico (GMPc) importante para la estimula- ción de la síntesis del factor de necrosis tumoral, que en última instancia conlleva a una mejor función microbicida. Otros factores son: la presencia de múltiples inclusiones lisosomales intracitoplasmáticas y una liberación inadecuada de la enzima B-glucuronidasa; todo esto se traduce en una pobre actividad bactericida ${ }^{1,2,8}$.

Una asociación con inmunosupresión deriva del hecho de encontrar pacientes afectados con antecedente de recibir prolongados tratamientos con agentes quimioterapéuticos o inmunosupresores. Se aportan casos después de transplante de órganos en tratamiento con inmunosupresión, también con el Síndrome de Inmunodeficiencia Adquirida (SIDA), Lupus eritematoso sistémico y colitis ulcerativa ${ }^{1}$, todos ejemplos de enfermedades con alteración del estado inmune.

Han sido numerosos los casos aportados de MLP en asociación con neoplasias, como área de compromiso focal en el sitio de aparición del tumor sin compromiso de otros órganos, el más frecuente ha sido el adenocarcinoma colorrectal ${ }^{1}$.

Una etiologia genética se propone después de su aparición en una familia ${ }^{1}$.

Actualmente una teoría que corresponde más a una combinación de algunas de las anteriores, propone que la enfermedad está relacionada a un defecto lisosomal acompañado de un ensamblaje anormal de los microtúbulos de los macrófagos que lo llevan a un estado bactericida ineficaz, es decir una teoría infecciosa con factores propios del huésped que lo hacen susceptible a padecer la enfermedad. Los microtúbulos son los responsables del proceso de invaginación y degranulación de los lisosomas, lo cual es un paso esencial en la fagocitosis bacteriana. Este proceso de ensamblaje de los microtúbulos es estimulado por el GMPc e inhibido por el Adenosin monofosfato cíclico (AMPc) $^{2,13,27}$. Una función lisosomal efectiva depende también de la presencia de la enzima B-glucuronidasa y de un estado celular en equilibrio iónico. Una alteración en el estado normal de la célula con una disminución del radio GMPc:AMPc, sumado a una disminución en la liberación de enzimas, son los principales factores de riesgo en el huésped y parece ser la explicación propuesta que predomina en la enfermedad y favorece su desarrollo ${ }^{2,13}$. 


\section{CLÍNICA}

El tracto urinario es el sitio más comúnmente afectado por la MLP y está bien documentado que el $80-90 \%$ de los pacientes padecen infección persistente por microorganismos coliformes. La enfermedad con compromiso genitourinario es más frecuente en el sexo femenino (4:1) con pico de incidencia en los mayores de 50 años, aunque el rango de edad de pacientes afectados aportados va desde las 6 semanas de vida hasta los 85 $\operatorname{años}^{2,20}$. Clínicamente hay tres formas de presentación:

- como infección de las vías urinarias en muje-

res adultas

- como enfermedad de localización extravesical con presencia de masa

- como una entidad asociada a inmunodeficiencias.

Sin embargo no existe un cuadro clínico o radiológico característico de la enfermedad ${ }^{21}$. Habitualmente se presentan con dolor abdominal difuso, pérdida de peso, diarrea, hematoquezia, hematuria y fiebre. Pero los síntomas dependen del órgano comprometido. El compromiso vesical se asocia a sintomas irritativos urinarios y hematuria; cuando es ureteral se presenta estenosis y obstrucción secundaria que luego, si existe compromiso bilateral puede desencadenar una insuficiencia renal ${ }^{2,20}$. La MLP con compromiso del parénquima renal se presenta con fiebre alta, dolor o masa palpable en dorso. En el 64\% de los casos la enfermedad afecta ambos riñones ${ }^{2}$ y es el tipo de afección genitourinaria que más elevada tasa de muerte presenta en las estadísticas. Tradicionalmente se presenta hasta de un $70 \%{ }^{19}$, aunque en la actualidad con el advenimiento de mejores métodos diagnósticos y la instauración del tratamiento mas temprano, es raro la muerte. Es de mencionar que el daño del parénquima conlleva a una nefritis intersticial inicial progresiva (destrucción del intersticio) que finalmente lleva a un reemplazo del parénquima por tejido fibrótico y por ende a una insuficiencia renal que lleva a la necesidad de terapia de reemplazo renal $^{19}$. A diferencia del compromiso vesical, la MLP renal es una enfermedad progresiva y destructiva del parénquima que puede extenderse más allá del riñón y es potencialmente fatal ${ }^{27}$; también está descrito en la literatura un caso de glomerulonefritis post-infecciosa secundaria a la presencia de bacterias coliformes en el parénquima renal ${ }^{23}$. En la próstata es una enfermedad rara y se presenta con una glándula dura y elevaciones del PSA ${ }^{2}$, incluso existe la aportación de un caso de presencia de carcinoma prostático en combinación con malacoplaquia, diagnosticado después de la evaluación patológica del espécimen obtenido por cirugía radical ${ }^{24}$. En testículo los síntomas son vagos y en algunos casos con signos inflamatorios o presencia de masa, simulando un tumor ${ }^{2}$. Corresponde al $12 \%$ de los casos con compromiso genitourinario, casi siempre es unilateral y más común en el lado derecho. Característicamente se presenta con un aumento marcado del tamaño testicular y se palpa fijo a la pared escrotal. Es una enfermedad inflamatoria destructiva, con cambios reactivos en la túnica albuginea y hasta en un tercio de los casos puede existir afección epididimaria concomitante ${ }^{28}$.

También está descrito el compromiso en riñón ${ }^{25} \mathrm{y}$ uréter post-transplante ${ }^{26}$, posiblemente explicado debido al prolongado tratamiento con drogas inmunosupresoras (azatriopina), presentándose como un cuadro de fallo renal que puede conllevar a la anuria o infección urinaria persistente que característicamente tiene una pobre tasa de curación a los tratamientos tradiciona$\operatorname{les}^{25}$.

La enfermedad es difícil de diagnosticar si sólo se tiene en cuenta la clínica, y son típicamente lesiones que simulan enfermedad maligna, por lo que su diagnóstico requiere confirmación histológica $^{4,8,21}$.

Durante un seminario de patología realizado en 1966, solamente el 10\% de los patólogos en estudios histológicos hicieron el diagnóstico de esta entidad ${ }^{3}$.

\section{DIAGNÓSTICo}

Definitivamente el diagnóstico de esta entidad es histopatológico, por lo que la biopsia es esencial para su confirmación además de ayudar a excluir otras patologias. Macroscópicamente la MLP produce lesiones únicas o múltiples caféamarillas o café-anaranjadas, dicha lesión se genera en la submucosa. Microscópicamente, independiente de su localización, se caracteriza por un infiltrado difuso de histiocitos de gran 
citoplasma, abundante e intensamente PAS positivo, llamadas células de Von Hansemann. Se postula su formación como consecuencia de un defecto en la acción bactericida por parte de las células encargadas, conllevando a la formación y presencia de grandes fagolisososmas con fragmentos bacterianos no lisados intra y/o extracelulares, que posteriormente se pueden calcificar. La calcificación de esos fragmentos bacterianos parcialmente digeridos produce los cuerpos de Michaelis-Gutmann, condición histopatológica sine qua non de $\mathrm{MLP}^{4,16}$, que tienen una apariencia característica de "tiro en diana" y miden de 5 a 10 micras $^{20}$. El $80-90 \%$ de los casos presentan urocultivos positivos para bacilos gram-negativos, de los cuales la mayoría son por E. coli ${ }^{17}$.

No existe un método imagenológico que pueda diagnosticar MLP con certeza.

Se enumeran los métodos presentados en la literatura para diagnóstico de esta entidad o que sugieren su presencia:

Citología urinaria: Es posible detectar la presencia de células con cuerpos de MichaelisGutmann en muestra de orina evaluadas por citología $^{17}$.

Cistoscopia: Aunque clásicamente se describe como lesión característica la presencia de placas sobreelevadas de consistencia blanda y color amarillento, actualmente se describen tres tipos de lesiones o fases evolutivas ${ }^{18}$

- Nodular: que es la forma clásica asociada o no a ulceración o necrosis central.

- Ulcerada: lesiones con bordes sobreelevados y fondo color amarillento.

- Pseudotumoral: lesiones verrucosas, elevadas con bordes hipervascularizados.

Ecografia: Considerado el método imagenológico más utilizado en la evaluación inicial de la patología urológica, se debe tener presente los hallazgos característicos de esta entidad. En riñón en etapas iniciales no es concluyente, sólo un incremento en la ecogenicidad del parénquima, en estadios avanzados se observa una perdida del parénquima y una disminución del tamaño, la hidronefrosis se presenta cuando existe compromiso distal a la pelvis renal. En vejiga se suele observar múltiples lesiones polipoides que usualmente son menores a $1 \mathrm{~cm}$ pero pueden crecer hasta más de $3 \mathrm{~cm}$, con una predilección por el trígono, algunas veces con extensión de las lesiones dentro de los uréteres distales ${ }^{20}$.

Urografia excretora: Lo usual es observar en el sistema colector imágenes consistentes con defectos de llenado, con apariencia de masas y si el compromiso es renal, se observa distorsión del sistema pelvicalicial. En casos de obstrucción distal por estrechez, se observa hidroureteronefrosis secundaria.

Tomografia: Dependiendo del compromiso y la cronicidad del cuadro, se observan imágenes simulando infiltración neoplásica en riñón con presencia de masas hipercaptantes, con posibilidad de heterogeneidad por necrosis focal y presencia de abscesos. También se pueden ver múltiples conglomerados compatibles con adenopatías en retroperitoneo, de tamaño significativo, a las cuales se les puede observar lesión central hipodensa en relación con centro necrótico. En vejiga se puede apreciar engrosamiento de la pared, simulando neoformación ${ }^{17}$.

Tomografia con emisión de positrones (PET): Cada vez se describe más acerca del uso del PET en el diagnóstico de enfermedades de origen maligno, que son sinónimo de una elevada tasa de metabolismo celular, además también en enfermedad neurológica y cardiaca aporta datos valiosos. Los isótopos marcados con compuestos orgánicos, derivados de la glucosa, siendo el más utilizado la 5-fluoro-deoxi-glucosa, que son utilizados en este examen se acumulan de manera selectiva en ciertos tejidos y luego captados por tomografía y reconstrucciones se pueden plasmar en gráficos y observar los resultados, resaltando las zonas de mayor captación. Las enfermedades infecciosas e inflamatorias son entonces un diagnóstico diferencial de patologías evaluadas por $\mathrm{PET}$, de ahí su aplicabilidad en el diagnóstico de MLP, principalmente renal ${ }^{27}$.

Resonancia Nuclear Magnética: Cuando el compromiso es del tracto urinario superior, se observa crecimiento del parénquima renal o pér- 
dida de éste, con presencia de múltiples imágenes hipocaptantes en corteza y médula, y cuando es la vejiga, se muestra un engrosamiento de la pared $^{23}$.

\section{TRATAMIENTO}

La piedra angular del tratamiento de forma prolongada es un antibiótico que tenga una excelente penetración a través de la membrana celular. Las fluoroquinolonas son efectivas en un 80$90 \%$ y son las que tienen mayor respaldo en la literatura ${ }^{3}$, desde su presentación inicial de tratamiento exitoso en MLP a principios de los ' $90^{19}$, por su fácil paso a través de la pared celular del macrófago e histiocito y alcanzar altas concentraciones intracitoplasmáticas, son consideradas la elección; también están descritas la rifampicina, el trimetropin-sulfametoxasol y la gentamici$\mathrm{na}^{2,17}$. Pacientes en tratamiento inmunosupresor lo aconsejado es suspenderlo en lo posible durante el periodo de tratamiento.

Como parte del tratamiento médico de la MLP, se anota la restauración de la función fagocitaria, para ello se describen dos compuestos: La adición de vitamina $\mathrm{C}$, aunque discutida, a altas dosis parece tener efecto en el estado celular iónico e incrementa el radio GMPc:AMPc. y el betanecol, droga agonista colinérgica que incrementa los niveles de GMPc intracelular. Ambos finalmente mejoran la función lisosomal y por ende potencian la fagocitosis.

El pronóstico de la MLP suele ser favorable, aunque no siempre es un proceso benigno, pues en situaciones de compromiso extravesical suele ser una enfermedad agresiva con posibles complicaciones fatales ${ }^{17}$. La cirugía está limitada a situaciones donde el tratamiento conservador es ineficaz. La nefrectomía, al igual que la orquidectomia, es necesaria en caso de enfermedad unilateral, avanzada y con compromiso del estado general del paciente, sumados a tratamiento médico logran ser curativas. La enfermedad con compromiso prostático requiere de un periodo más prolongado de tratamiento con antibióticos y vitamina C. Se presentan periodos tan prolongados de hasta seis meses, el PSA debe disminuir una vez instaurado el tratamiento y es considerado en la literatura como un marcador de seguimiento y respuesta al tratamiento. En caso de obstrucción ureteral se debe realizar además del tratamiento médico una derivación. En los casos de compromiso vesical con presencia de grandes masas, está indicada la resección endoscópica amplia y lo más temprana posible, favoreciendo el tratamiento médico asociado y la eliminación de posibles focos sépticos ${ }^{17}$.

El compromiso retroperitoneal suele ser muy agresivo y puede llevar a la muerte del paciente ${ }^{17}$. En un estudio de las series aportadas después de 1990, la tasa de sobrevida fue superior al $90 \%$ en los pacientes afectados ${ }^{19}$. Estos pacientes siempre se deben acompañar de una revisión periódica, evaluando la posibilidad de recidiva a largo plazo.

En conclusión, la MLP es un proceso inflamatorio granulomatoso crónico poco frecuente, con predominio en el sexo femenino de edad avanzada y típicamente compromete el tracto genitourinario. Su extensión extravesical suele ser rara y más agresiva. El manejo afortunadamente en la mayoría de los casos incluye sólo medidas terapéuticas, como lo es el tratamiento con fluoroquinolonas idealmente. Las intervenciones quirúrgicas sólo están relegadas a compromisos extensos con inestabilidad del paciente afectado. El curso con el tratamiento adecuado suele ser benigno. Todo paciente con este diagnostico debe seguir un curso de revisiones periódicas por la posibilidad de recidiva. Presentamos seis casos con interés académico y de enseñanza en una entidad en la que su diagnóstico primero se debe sospechar.

\section{REFERENCIAS}

1. Feldman: Sleisenger \& Fordtran's Gastrointestinal and Liver Disease. 2002; $7^{\text {th }}$ ed. Pg 2306-2307.

2. Dasgupta P, Womack C, Turner AG, Blackford HN Malacoplakia: von Hansemann's disease. Review. BJU International 1999; 84(4):464-469.

3. Dohle G, Zwartendijk J, Van krierken JH. Urogenital malacoplakia treated with fluoroquinolones. J Urol 1993; 150(5 Pt 1):1518-1520.

4. Gamboa A, Lavenant I, Olvera JE, Santiago H. Malacoplaquia en colon y retroperitoneo. Informe de dos casos. Patología (Mex.) 1994;32:185-189.

5. Schwartz DA, Orden PO, Blumberg HM, Honig E. Pulmonary malakoplakia in a patient with AIDS. Differential diagnostic considerations. Arch Pathol Lab Med 1990; 114(12):1267-1272.

6. Volk E, Parker JC Jr, Tepper S. Cerebral malakoplakia associated with neonatal herpes virus infection. Ann Clin Lab Sci 1992;22:300-306.

7. Zuk RJ, Neal JW, Baithun SI. Malakoplakia of the pancreas. Virchows Arch A Pathol Anat Histopathol. 1990; 417(2):181-184. 
8. Jeffrey PB, Chandrasoma P, Greaves T. Fine needle Aspiration cytology of malacoplakia of the thyroid. A case report. Acta Cytol. 1996; 40(5):970-974.

9. Simpson C, Strong NP, Dickinson J, Young FI, SandfordSmith JH. Medical management of ocular malakoplakia. Ophthalmology. 1992;99(2):192-196.

10. Palazzo JP, Ellison DJ, Garchia IE, Langer C, Scher RM, Hoffman JP, Petersen RO. Cutaneous malakoplakia simulating relapsing malignat lymphoma. J Cutan Pathol 1990; 17(3):171-175.

11. Nayar RC, Garg I, Alapatt JJ. Malakoplakia of the temporal bone in a nine month old infant. J Laryngol Otol 1991; 105(7):568-570.

12. Mariño A, Ramírez JA, Rivera M, Casaubon PR, Mata N, Mora MA. Malacoplasia intestinal en la infancia. Informe de cinco casos. Bol Med Hosp. Infant Mex 1990; 47(4):261-269.

13. Van Crevel R, Curfs J, van der Ven AJAM, Assmann K, Meis JF, van der Meer JW. Functional and morphological monocyte abnormalities in a patient with malakoplakia. The Am J Med 1998; 105(1):74-77.

14. Qualman SJ, Gupta PK, Mendelsohn G. Intracellular E. coli in urinary malakoplakia: A reservoir of infection and its therapeutic implications. Am J Clin Pathol. 1984; 81(1):35-42.

15. Van Furth R, van't Wout JW, Wertheimer PA, Zwartendijk J. Ciprofloxacin for treatment of malakoplakia. Lancet. 1992; 339(8812):148-149.

16. Hurwitz G, Reimund E, Moparty KR, Hellstrom WJ. Bilateral renal parenchimal malacoplakia: a case report. J Urol. 1992; 147(1):115-117.

17. Pozo Mengual B, Burgos Revilla FJ, Briones Mardones G, Linares Quevedo A, Garcia-Cosio Piqueras M. Malacoplaquia vesical con afectación ganglionar y curso agresivo. Actas Urol Esp. 2003; 27(2):159-163.

18. Vicente J, Algaba F. Macro y microscopía de las cistopatías (IV). Malacoplaquia vesical. Anales Fund Puigvert 1980;10:124

19. Tam VKK, Kung WH, Li R, Chan KW. Renal parenchymal malacoplakia: A rare cause of ARF with a review of recent literature. Am J Kidney Dis. 2003; 41(6):E2 1;1-5.

20. Steele B, Vade A, Lim-Dunham J. Sonographic appearance of bladder malacoplakia. Pediatr Radiol. 2003;33(4): 253-255.
21. Vélez A, Ángel A, Uribe C, Raad R, Uribe JF, Jaramillo S, et al. Malacoplaquia renal, duodenal y retroperitoneal. Presentación de un caso. Medicina U.P.B. Medellín 2001; 20(1):43-48.

22. Raad R, Vélez A, Ángel A, Uribe JF. Visión de la Malacoplaquia a través de una presentación inusual: La próstata. Rev Col Urol. 1997;6:93-95.

23. Yang AH, Tarng DC, Chen JY, Lu SH. Post-infectious glomerulonephritis in a patient with vesicorenal malacoplakia-coincidence or causal relationship? Nephrol Dial Transplant. 2000; 15(7):1060-1062.

24. Répássy DL, Ivanyi A, Csata S, Tamas G. Combined occurrence of prostate carcinoma and malacoplakia. Pathol Oncol Res. 2002; 8(3):202-203.

25. Streem SB. Genitourinary malacoplakia in renal transplant recipients: pathogenic, prognostic and therapeutic considerations. J Urol. 1984;132(1):10-12.

26. Teahan SJ, O`Malley KJ, Little DM, Bakthavatsalam R, Kay EW, Hickey DP. Malacoplakia of transplant ureter resulting in anuric renal failure. J Urol. 1999; 162(4): 1375-1376.

27. Sheerin NS, Bhatacharia KF, Webb MC. Positron emission tomography in a patient with renal malacoplakia. AJKD 2003; 42(3):E17;1-4.

28. Carvajal A, Vélez A, Escobar AM, Restrepo JM, Aristizábal JM, Robledo M. Malacoplaquia de testículo. Rev. CAU 2003;15(1):52-53.

29. Ballesteros JJ. Malacoplaquia urogenital. Presentación de 4 casos y revisión de la literatura. Arch Esp Urol. 2001; 54(8):768-776.

Dr. J.G. Velásquez López

E-mail: juangvl@gmail.com

(Trabajo recibido el 20 de octubre de 2005) 